University of Massachusetts Amherst

ScholarWorks@UMass Amherst

Chemistry Department Faculty Publication Series

Chemistry

1996

\title{
Determination of arsenic in gold by flow injection inductively coupled plasma mass spectrometry with matrix removal by reductive precipitation
}

P BecotteHaigh

JF Tyson

E Denoyer

MW Hinds

Follow this and additional works at: https://scholarworks.umass.edu/chem_faculty_pubs

\section{Recommended Citation}

BecotteHaigh, P; Tyson, JF; Denoyer, E; and Hinds, MW, "Determination of arsenic in gold by flow injection inductively coupled plasma mass spectrometry with matrix removal by reductive precipitation" (1996). SPECTROCHIMICA ACTA PART B-ATOMIC SPECTROSCOPY. 1078.

Retrieved from https://scholarworks.umass.edu/chem_faculty_pubs/1078 


\title{
Determination of arsenic in gold by flow injection inductively coupled plasma mass spectrometry with matrix removal by reductive precipitation
}

\author{
Paul Becotte-Haigh ${ }^{\mathrm{a}}$, Julian F. Tyson ${ }^{\mathrm{a}, *}$, Eric Denoyer ${ }^{\mathrm{b}}$, Michael W. Hinds ${ }^{\mathrm{c}}$ \\ ${ }^{a}$ Department of Chemistry, Box 34510, University of Massachusetts, Amherst, MA 01003-4510, USA \\ ${ }^{b}$ Perkin-Elmer Corporation, 761 Main Ave., Norwalk, CT 06859, USA \\ 'Reyal Canadian Mint, 320 Sussex Drive, Ottawa, Ont. K1A 0G8, Canada
}

Received 19 March 1996; accepted 22 April 1996

\begin{abstract}
Arsenic was determined in gold by flow injection hydride generation inductively coupled plasma-mass spectrometry following a batch mode reductive precipitation removal of the interfering gold matrix. A solution of potassium iodide, L-ascorbic acid, and hydrochloric acid was used as the reluctant. The recovery of gold by precipitation and filtration was $99 \pm 3 \%$. The detection limit for arsenic in gold was $55 \mathrm{ng} \mathrm{g}^{-1}$ in the solid. The concentration of arsenic that was determined in the Royal Canadian Mint gold sample FAU-10 was $29.7 \mu \mathrm{g} \mathrm{g}^{-1}$ in the solid; this value was indistinguishable, with $95 \%$ confidence, from values determined at the Royal Canadian Mint by graphite furnace atomic absorption spectrometry and by inductively coupled plasma-mass spectrometry. The standard deviation for four replicate determinations of the arsenic in FAU-10 was $0.972 \mu \mathrm{g}$ $\mathrm{g}^{-1}$ in the solid.
\end{abstract}

Keywords: Arsenic; Flow injection; Hydride generation; ICP-MS; Matrix removal; Reductive precipitation

\section{Introduction}

The determination of the common impurities in gold is important in assessing the value, physical properties, and point of origin of a sample of gold [1-3]. Arsenic is often present at ppm concentrations in gold. Digestion and dilution of the sample further reduce the concentration of arsenic to be determined, creating a need for a very sensitive analytical method. A method for this determination should also be precise so that sample homogeneity may be determined

\footnotetext{
* Corresponding author.
}

[1]. In addition, the method should require a small sample size in order to minimize the cost.

Electrothermal atomic absorption spectrometry (ET-AAS) with batch anion-exchange removal of the gold matrix [4], and laser ablation inductively coupled plasma mass spectrometry (LA-ICP-MS) $[1,3]$ have both been used to determine trace elements in gold samples. Some of the advantages of the LAICP-MS method are: solid sampling, microsampling, sensitivity, and multi-element capability. The main drawbacks to LA-ICP-MS are the lack of suitable calibration and certified reference materials, and poorer precision relative to solution analysis [5].

A method for trace element determinations in gold using direct nebulization into the ICP-MS would 
potentially suffer from several interferences. The conventional aqua regia gold digestion procedure introduces $\mathrm{Cl}^{-}$, which produces the polyatomic interference ${ }^{40} \mathrm{Ar}^{35} \mathrm{Cl}^{+}$on mono-isotopic ${ }^{75} \mathrm{As}^{+}$. The total dissolved solids should not exceed $0.1-05 \% \mathrm{~m} / \mathrm{m}$ in the diluted sample or deposition of material on the sample and skimmer cones will cause drift and sensitivity loss problems [5-7]. Dilution of the matrix to reduce the total dissolved solids also dilutes the arsenic. Gold introduced could also suppress the analyte signal by its space charge effect [8-10].

The application of flow injection (FI) techniques to atomic spectroscopy in order to reduce interferences is well documented [11-17]. Several workers have applied FI to ICP-MS [5,7,18-21]. Sample and reagent consumption, as well as the total amount of dissolved solids that enter the ICP-MS are reduced with FI techniques.

Hydride generation (HG) is often used to increase the transport efficiency and therefore the sensitivity for certain vapor forming elements, such as As $[18,20,22]$. Another advantage of HG is that the analyte is removed from interfering matrix constituents. A depressive interference upon the hydride signal is often encountered, however, because of the adsorption of the hydride on finely divided transition metal particles that may be precipitated by the reluctant $[23,24]$. Preliminary experiments had shown this to be the case for the determination of As in gold [25], despite the successful use of the kinetic discrimination with a FI system for the determination of As in nickel [26].

Table 1

Operating conditions for the Elan 5000

\begin{tabular}{ll}
\hline $\begin{array}{l}\text { Instrumental parameters } \\
\text { r.f. power/W }\end{array}$ & 1000 \\
$\begin{array}{l}\text { Argon gas flow: } \\
\left.\text { Outer gas flow rate/( } \mathrm{min}^{-1}\right)\end{array}$ & 15 \\
Intermediate gas flow rate/( $\left.\mathrm{min}^{-1}\right)$ & 0.80 \\
Aerosol carrier gas flow rate/( $\left.\mathrm{min}^{-1}\right)$ & $0.9-1.1$ \\
Sample and skimmer cones & nickel \\
Mass spectrometer running pressure/Pa & $130 \times 10^{-6}$ \\
Data acquisition parameters & \\
Mode & Peak hop transient \\
Dwell time/ms & 40 \\
Points per peak & 1 \\
Readings per replicate & 250 \\
Number of replicates & 5 \\
\hline
\end{tabular}

The Royal Canadian Mint (RCM) requires a method for the determination of As in the range $1-50 \mu \mathrm{g} \mathrm{g}^{-1}$ range in gold laser ablation standards. A graphite furnace method for this determination exists, but the characterization of reference materials necessitates a number of validations.

The aim of this study was the development of an FI-HG-ICP-MS method for the determination of As in RCM gold standards. A batch mode precipitation procedure for the removal of gold, which interferes with HG, is described.

\section{Experimental}

\subsection{Instrumentation}

An Elan 5000 ICP mass spectrometer (PerkinElmer SCIEX, Norwalk, CT, USA) equipped with a FIAS-200 (Bodenseewerk Perkin-Elmer, Überlingen, Germany) was used for this work. The ICP-MS operating conditions are summarized in Table 1 . The operating conditions (nebulizer flow and ion optics settings) were optimized by pumping a $1 \mathrm{ppb}(\mathrm{m} / \mathrm{m})$ As(III) standard through the carrier line, and generating the hydride continuously. The sensitivity observed during this optimization was more than adequate for the analysis, so that the reagent concentrations and manifold parameters did not have to be optimized further. The FIAS operating program is summarized in Table 2.

The FI manifold is shown in Fig. 1. The gas-liquid separator (GLS) (Perkin-Elmer, Norwalk, CT, USA) is the same as the one described by Welz and Schubert-Jacobs [27], except that the device was filled with glass beads to the top of the waste drain. The nebulizer was replaced with a Teflon adapter that screwed directly to the torch mount and had a $2 \mathrm{~mm}$ i.d. central channel. The GLS was connected directly to the Teflon torch adapter via $1 \mathrm{~m}$ of $1.24 \mathrm{~mm}$ i.d. Teflon tubing. The injection volume was $500 \mu$ l.

\subsection{Reagents and sample preparation}

All reagents were of analytical reagent grade unless otherwise stated. All reagents and samples were prepared with distilled, deionized water (E-Pure, Barnsted, Boston, MA). Fisher Scientific (Fair 


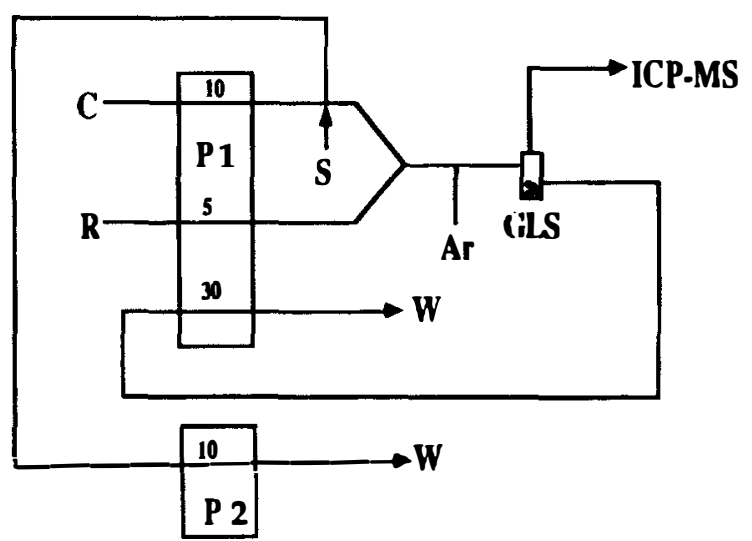

Fig. 1. Flow injection manifold for hydride generation ICP-MS. All manifold tubing was $0.762 \mathrm{~mm}$ i.d. The length of the tubing between the acid carrier and reductant merging point and argon addition point was $8 \mathrm{~cm}$. The length of the tubing between the argon addition point and the gas-liquid separator was $30 \mathrm{~cm}$. C: $10 \% \mathrm{HCl}$ carrier stream; $\mathrm{R}: \mathrm{NaBH}_{4}$ reductant stream; S: sample injected $(500 \mu \mathrm{l})$; W: waste; P1 and P2: pumps; GLS: gas-liquid separator; Ar: argon purge stream. Reagent and waste flow rates are shown on the pumps in $\mathrm{ml} \mathrm{min}^{-1}$.

Lawn, NJ, USA) brand concentrated hydrochloric and nitric acids were used throughout this work.

The sodium tetrahydroborate solution was prepared fresh daily by dissolving sodium tetrahydroborate (Fisher Scientific) in $0.05 \%(\mathrm{~m} / \mathrm{m})$ sodium hydroxide (certified, Fisher Scientific), then suction filtering the solution through \#1 Whatman filter paper. A 1000 $\mathrm{ppm}(\mathrm{m} / \mathrm{v})$ stock solution of $\mathrm{As}(\mathrm{V})$ was prepared by dissolving sodium arsenate (certified, Fisher) in 10\% (v/v) nitric acid. A $500 \mathrm{ppb}(\mathrm{m} / \mathrm{m})$ As(III) stock solution was prepared by adding $20 \mathrm{ml}$ of $10 \%$ $(\mathrm{m} / \mathrm{v})$ potassium iodide (Aldrich, Milwaukee, WI) $10 \% \mathrm{~L}$-ascorbic acid (Fisher), and $20 \mathrm{ml}$ concentrated hydrochloric acid to $0.1 \mathrm{ml}$ of the $1000 \mathrm{ppm}(\mathrm{m} / \mathrm{v})$ $\operatorname{As}(\mathrm{V})$ stock solution in a $250 \mathrm{~m}$ Nalgene bottle, diluting to $200 \mathrm{~g}$, and allowing the solution to stand for $45 \mathrm{~min}$.
Four portions of the gold sample, each between 0.05 and $0.17 \mathrm{~g}$ (FAU-10, $29.4 \mathrm{ppm}(\mathrm{m} / \mathrm{m})$ As) supplied by the Royal Canadian Mint (RCM) were each dissolved by placing the material in a $50 \mathrm{ml}$ beaker with $1 \mathrm{ml}$ concentrated nitric acid and $3 \mathrm{ml}$ concentrated hydrochloric acid, covering with a watchglass, and heating slowly until the resulting solution evaporated to approximately half of its original volume. Each solution was then diluted with $1 \%(\mathrm{v} / \mathrm{v})$ hydrochloric acid to yield a yellow solution containing $0.05 \% \mathrm{Au}(\mathrm{m} / \mathrm{m})$. Forty gram aliquots of the $0.05 \%(\mathrm{~m} / \mathrm{m})$ FAU-10 sample solutions were reduced by adding $20 \mathrm{ml}$ of $10 \%(\mathrm{~m} / \mathrm{v}) \mathrm{L}$ ascorbic acid, $10 \%(\mathrm{~m} / \mathrm{v}) \mathrm{KI}$ solution, $20 \mathrm{ml}$ hydrochloric acid and diluting to $200 \mathrm{~g}$. An opaque brown precipitate formed in the samples upon the addition of the $\mathrm{KI} / \mathrm{L}$-ascorbic acid solution. This precipitate was removed by filtering through glass wool, dissolved in aqua regia, and diluted to $200 \mathrm{ml}$ to produce a yellow solution. The precipitate immediately assumed a metallic gold appearance on addition of aqua regia. A $0.1 \mathrm{ml}$ aliquot of the solution in which the precipitate was dissolved was diluted to $100 \mathrm{~g}$. The filtrate was clear and colorless.

\subsection{Standards}

Standards were prepared by dissolving and prereducing/filtering $0.082 \mathrm{~g}$ high purity gold $(99.999 \%, \mathrm{RCM})$ in the same manner as the samples, and adding appropriate amounts of the $500 \mathrm{ppb}(\mathrm{m} / \mathrm{m})$ As(III) standard before the final dilution, to produce 0 , $0.99,2.5$ and $5.0 \mathrm{ppb}(\mathrm{m} / \mathrm{m})$ As(III) standards. This procedure was followed in an attempt to match the sample matrix composition. These calibration standards were used for the determination of As in the samples. A set of calibration standards was prepared by spiking $10 \%$ hydrochloric acid with the $500 \mathrm{ppb}$ $(\mathrm{m} / \mathrm{m})$ As(III) solution to produce $0,1.0,2.0,4.0$ and $6.0 \mathrm{ppb}(\mathrm{m} / \mathrm{m})$ As(III) standards for comparison with

Table 2

FIAS 200 program

\begin{tabular}{lllll}
\hline Step & Time/s & Pump 1/(rev $\left.\min ^{-1}\right)$ & Pump 2/(rev $\left.\mathrm{min}^{-1}\right)$ & Valve position \\
\hdashline Pre-sample & 20 & 120 & 120 & Rinse/fill loop \\
1 & 20 & 120 & 100 & Fill loop \\
2 & 15 & 120 & 0 & Inject \\
\hline
\end{tabular}


Table 3

Results (in $\mu \mathrm{g} / \mathrm{g}$ ) for the determination of As in FAU-10

\begin{tabular}{lllc}
\hline Method & Concentration determined & Standard Dev. & Replicates \\
\hline FI-HG-ICP-MS & 29.7 & 0.972 & 4 \\
with pre-reduction & & & 8 \\
ICP-MS & 28.3 & 1.26 & 10 \\
GFAAS $^{\text {a }}$ & 30.4 & 1.10 & 8 \\
\hline
\end{tabular}

${ }^{a}$ Data obtained by the Royal Canadian Mint.

the matrix matched standards. Another set of calibration standards $(0,0.053,0.026,0.13,0.26,0.93$ and $3.5 \mathrm{ppb}(\mathrm{m} / \mathrm{m})$ As(III) was subsequently prepared by pre-reducing and spiking gold solutions to investigate the calibration response at lower concentrations, and to calculate a detection limit. A $10 \mathrm{ppb}(\mathrm{m} / \mathrm{m})$ gold solution was prepared as a single point calibration for the determination of the gold recovery by the precipitation. The gold determination was performed by FI ICP-MS with a single-line manifold. The gold content in a prereduced/filtered sample was also determined by this method.

\section{Results and discussion}

When a sample containing gold was injected a black precipitate formed downstream of the confluence point at which the sodium tetrahydroborate solution was merged. Once this precipitate formed subsequent injections of samples and standards gave no signal. It was hoped that this gold interference would be eliminated by separation of the gold by precipitation during sample pretreatment. However, it was considered possible that arsenic might coprecipitate with the gold, leading to inaccurate determinations.

\subsection{Gold recovery}

The concentration of gold in the solution in which the precipitate was dissolved would be 500 $\mathrm{ppb}(\mathrm{m} / \mathrm{m})$ if all of the gold was recovered by the precipitation/filtration/dissolution procedure mentioned above. The gold content of the solution was $492 \pm 16 \mathrm{ppb}(\mathrm{m} / \mathrm{m})$. This value corresponds to $99 \pm 3 \%$ recovery ( $95 \%$ confidence). The gold content of a pre-reduced/filtered sample solution was determined to be $5.1 \pm 0.8 \mathrm{ppb}(\mathrm{m} / \mathrm{m}, 95 \%$ confidence). Gold was shown to be completely removed from the matrix by a batch mode reduction prior to analysis.

\subsection{Determination of arsenic}

The results for the determination of arsenic in FAU10 gold by FI-HG-ICP-MS are compared with the values obtained by the RCM by ICP-MS and graphite furnace atomic absorption spectrometry (GFAAS) in Table 3. The values determined in this work are indistinguishable from the values determined by the RCM, with $95 \%$ confidence. Therefore, arsenic was not lost during the gold precipitation.

The sensitivity of the matrix matched standards calibration was 200 kilo counts per second (kcps) per ppb As(III), as compared to $180 \mathrm{kcps}$ per ppb As(III) for the non-matrix matched standards. The difference between these values may be due to the instrumental drift that was observed. The correlation coefficient for each of these calibrations was greater than 0.9999. Approximately 60 injections per hour were possible with the FIAS program used.

The calibration that was performed using the lower concentration matrix-matched standards had a correlation coefficient of 0.999 . The detection limit for this method, based upon 3 standard deviations of the blank response, was $55 \mathrm{ppb}(\mathrm{m} / \mathrm{m})$ As in the solid sample. Since the RCM requires that the method detect arsenic at concentrations down to $1 \mathrm{ppm}(\mathrm{m} / \mathrm{m})$ in the solid, this method would be adequate for their purposes.

\section{Acknowledgements}

The provision and maintenance of the Perkin-Elmer Sciex Elan 5000 and FIAS 200 instruments at the 
Amherst campus by Perkin-Elmer are gratefully acknowledged.

\section{References}

[1] V.V. Kogan, M.W. Hinds and G.I. Ramendik, Spectrochim. Acta Part B, 49 (1994) 333.

[2] R.J. Puddephatt, The Chemistry of Gold, Elsevier, Amsterdam, 1978.

[3] R.J. Watling, H.K. Herbert, D. Delev and I.D. Abell, Spectrochim. Acta Part B, 49 (1994) 219.

[4] E. Ivanova and H. Berndt, Fresenius J. Anal. Chem., 340 (1991) 419

[5] P. Richner, J. Anal. At. Spectrom., 8 (1993) 927.

[6] C.W. McLeod, J. Anal. At. Spectrom., 2 (1987) 549.

[7] A.G. Coedo and M.T. Dorado, J. Anal. At. Spectrom., 9(1994) 1111.

[8] E.H. Evans and J.J. Giglio, J. Anal. At. Spectrom., 8 (1993) 1.

[9] G.R. Gillson and J.E. Douglas, Anal. Chem., 60 (1988) 1472.

[10] S.D. Tanner, L.M. Cousins and D.J. Douglas, Appl. Spectrosc., 48 (1994) 1367.

[11] J. Ruzicka and E.H. Hansen, Anal. Chim. Acta, 78 (1975) 145.
[12] J. Ruzicka and E.H. Hansen, Anal. Chim. Acta, 179 (1986) 1.

[13] K.K. Stewart, Anal. Chem., 55, 931A (1983).

[14] C.B. Ranger, Anal. Chem., 53, 20A (1981).

[15] J.F. Tyson, Analyst, 110 (1985) 419.

[16] J.F. Tyson, S.R. Bysouth, E.A. Greszczyk and E. Debrah, Anal. Chim. Acta, 261 (1992) 75.

[17] L. Nord and B. Karlberg, Anal. Chim. Acta, 145 (1983) 151.

[18] A. Stroh and U. Vollkopf, J. Anal. At. Spectrom., 8 (1993) 35.

[19] S. Dadfarnia and C.W. McCleod, Appl. Spectrosc., 48 (1994) 1331.

[20] J.R. Dean, H.G.M. Parry, R.C. Massey and L. Ebdon, ICP Information Newsletter, 15 (1990) 569.

[21] E.R. Denoyer and Q. Lu, Atomic Spectrosc., 14 (1993) 162.

[22] S. Branch, W.T. Corns, L. Ebdon, S. Hill and P. O'Neill, J. Anal. At. Spectrom., 6 (1991) 155.

[23] B. Welz and M. Schubert-Jacobs, J. Anal. At. Spectrom., 1 (1986) 23.

[24] B. Welz and M. Melcher, Analyst, 109 (1984) 569.

[25] C.P. Hanna, PhD dissertation, University of Massachusetts (1993).

[26] C.P. Hanna, J.F. Tyson and S.G. Offley, Spectrochim. Acta Part B, 47 (1992) 1065.

[27] B. Weiz and M. Schubert-Jacobs, At. Spectrosc., 12 (1991) 91. 